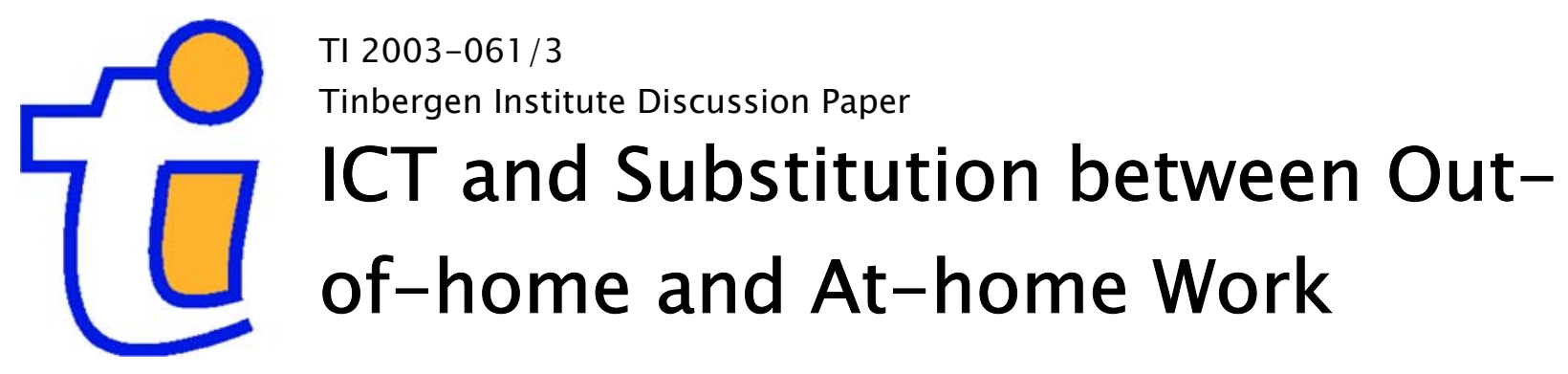

Thomas de Graaff

Piet Rietveld*

Faculty of Economics and Business Administration, Vrije Universiteit Amsterdam.

* Tinbergen Institute. 


\section{Tinbergen Institute}

The Tinbergen Institute is the institute for economic research of the Erasmus Universiteit Rotterdam, Universiteit van Amsterdam, and Vrije Universiteit Amsterdam.

Tinbergen Institute Amsterdam

Roetersstraat 31

1018 WB Amsterdam

The Netherlands

Tel.: $\quad+31(0) 205513500$

Fax: $\quad+31(0) 205513555$

Tinbergen Institute Rotterdam

Burg. Oudlaan 50

3062 PA Rotterdam

The Netherlands

Tel.: $\quad+31(0) 104088900$

Fax: $\quad+31(0) 104089031$

Please send questions and/or remarks of nonscientific nature to driessen@tinbergen.nl.

Most TI discussion papers can be downloaded at http://www.tinbergen.nl. 


\title{
ICT and substitution between out-of-home and at home work; the importance of timing
}

\author{
Thomas de Graaff Piet Rietveld \\ Faculty of Economics and Business Administration \\ Vrije Universiteit Amsterdam \\ De Boelelaan 1105, 1081 HV, Amsterdam, The Netherlands \\ tgraaff@feweb.vu.nl \\ prietveld@feweb.vu.nl
}

July 31, 2003

\begin{abstract}
This paper investigates the determinants of at home and out-of-home labor supply in the Netherlands in the 1990s, focusing on the presence of ICT technologies in households - in particular modem possession.

To investigate these determinants, a sequential hurdle model is estimated where people first decide to work and then decide to divide total labor supply in at home and out-of-home labor supply. To correct for possible endogeneity, the modem variable is estimated with use of instrumental variables. When we only consider office hours, possession of ICT facilities at home stimulates both at home and out-of-home labor supply. Thus, the two may be called complements from the ICT perspective. However, outside office hours, modem possession leads to less work out-of-home. During this part of the day the time worked less on the job is partly substituted by work at home. Thus, during this part of the week we find that substitution dominates. However, since labor supply during office hours dominates labor supply during the rest of the week we find complementarity as the main feature of overall labor supply. These results underline the importance of timing issues.

Keywords: Bivariate tobit; Labor supply; Modem possession; Netherlands; At home labor supply; Out-of-home labor supply; Teleworking
\end{abstract}




\section{Introduction}

In the 1990s, use and possession of personal computers and internet connections became common within households in many countries. It has been argued that this large-scale introduction of information and communication technology (ICT) would have a profound impact on daily activities. For example, claims have been made that ICT in the form of telecommuting would substantially reduce commuting travel (for a critical review see Salomon, 2000; Hjorthol, 2002). This would imply a shift from out-of-home labor supply to at home labor supply. ICT connections between home and work include access to the server at the office, to a person's own files and e-mail, and may also enable people to be present (although not physically) at meetings (videoconferencing), etcetera. On the other hand, the use of ICT could also promote at home labor supply outside office hours (weekends and evenings) where at home labor supply is then used to complement out-of-home labor supply. In order to address this issue, this paper focuses on the impact of the use of ICT on at home labor supply. Special attention is paid to the timing of at home labor supply and its correlation with out-of-home labor supply.

Unfortunately, statistics about telecommuting are scarce. For illustration, the Ministry of Transport, Public Works and Water Management in the Netherlands ${ }^{1}$ has only a rough estimate for the number of teleworkers in the Netherlands in 2001 of about 400,000 workers (which amounts to $3.7 \%$ of the labor force). For telecommuting, the Ministry uses the following definition: A teleworker is an individual who works partly at home (or somewhere else than at work) and who uses for that purpose information and communication technology. ${ }^{2}$ The ministry estimated that on average Dutch teleworkers work one or one and a halve days at home per week.

From the policy side, the stimulation of telecommuting - and its corresponding shift to at home labor supply - is advocated to be an important policy instrument for reducing congestion during peak-hours. Namely, traffic intensity in the Netherlands has increased since 1986 by $44 \%$, while the total length of the roads only increased with 14\% (Ministerie van Verkeer en Waterstaat, 2001). Therefore, similar to other European countries, congestion has become a serious policy issue. It has been argued that an increase in telecommuting with its deviant travel pattern in relation to normal commuting pattern could reduce congestion during peak hours, although the empirical basis for this hypothesis is rather weak.

Recently, much research has been done in the field of the adoption of telecommunication (see e.g. Yen, 2000; Mokhtarian, 1996a and 1996b) and whether there is substitution or complementarity between telecommuting and travel behavior (see e.g. Salomon, 2000; Mokhtarian, 1998). In addition, attention has also been given to the characteristics of individuals who work at home (see e.g. Olson, 1983; DeSanctis, 1984; Yap and Tng, 1990; Bélanger, 1998; Vilhelmson and Thulin, 2001). However, less research has been done into the impact of the use of ICT to the hours of working at home. Hjorthol (2002) is an exception for the relation between daily travel and the use of the personal computer in Norway. Therefore, the aim of this paper is to present an analysis of the hours of working both at home and out-of-home among the Dutch labor force in relation to ICT. To achieve this, we use a bivariate Tobit model with sample selection, in which we are able to relate the decision to work, the number of working hours at home and

\footnotetext{
${ }^{1}$ See also: http://www.minvenw.nl/cend/faz/telewerken/introductie/feitenencijfers.htm.

${ }^{2}$ This definition also includes workers who have to work home because of their occupation.
} 
the number of working hours out-of-home. For the presence of ICT within households, we use modem possession.

Characteristic for the Dutch labor force is the large number of people who work part-time (especially women) and the flexible behavior of the labor force. However, a substantial part of the female labor population work less hours than men, are more inclined than men to give up their job when conditions in a household change and have a lagging position on the Dutch labor market in the 1990s (Fortuijn, 1993). Therefore, we look at the male and female labor population separately. In addition, to examine timing effects, we split our sample in office hours and non-office hours.

The next section first provides a description of the data we use in this research. In addition, it offers the distribution of ICT appliances across socio-economic groups in the Netherlands and the distribution of working hours and travel time for an average working day. Thereafter, we proceed with the construction of an econometric model that is able to relate at home and out-of-home labor supply taking into account the participation decision. The succeeding section offers the variables used in the model, their measurement and the corresponding results. The last section concludes and provides a research agenda. 


\section{ICT in the Netherlands}

Table 1: Possession of ICT related appliances for different socio-economic groups (\%) (Netherlands, 1995).

\begin{tabular}{|c|c|c|c|}
\hline Variables & $\begin{array}{l}\text { possession of } \\
\text { a computer }\end{array}$ & $\begin{array}{l}\text { possession } \\
\text { of a modem }\end{array}$ & $\begin{array}{c}\text { possession of an } \\
\text { internet connection }\end{array}$ \\
\hline \multicolumn{4}{|l|}{ gender } \\
\hline male & 54.6 & 14.4 & 4.3 \\
\hline female & 51.5 & 12.0 & 3.4 \\
\hline \multicolumn{4}{|l|}{ partnership } \\
\hline partner & 53.4 & 13.7 & 3.6 \\
\hline no partner & 37.1 & 9.1 & 3.5 \\
\hline \multicolumn{4}{|l|}{ education } \\
\hline basic & 21.8 & 4.6 & 3.5 \\
\hline lower vocational & 35.8 & 5.5 & 1.6 \\
\hline medium vocational & 43.1 & 10.5 & 2.0 \\
\hline craft education & 52.9 & 10.0 & 2.0 \\
\hline high vocational & 56.4 & 19.1 & 5.5 \\
\hline college & 68.4 & 18.3 & 5.4 \\
\hline university & 78.6 & 26.0 & 9.2 \\
\hline \multicolumn{4}{|l|}{ family income (guilders) } \\
\hline$<2000$ & 33.4 & 6.6 & 2.9 \\
\hline $2000-3000$ & 42.6 & 7.9 & 2.2 \\
\hline $3001-4000$ & 54.9 & 12.6 & 3.8 \\
\hline$>4000$ & 68.2 & 20.6 & 5.8 \\
\hline
\end{tabular}

Source: SCP, 1995.

The data we use have been collected in 1995. At that time, the employed workers in the Netherlands worked on average 33.1 hours per week (including overwork). However, among the population large differences can be observed. Women worked on average 26.6 hours per week, while men worked 37.3 hours. Individuals who worked part-time spent 20.9 hours per week on their job, full-time workers 40.1 , and flexible workers 17.9 hours (CBS, 1997). Although the personal computer was not as common as nowadays, already $39 \%$ of the Dutch households were reported to be in the possession of a personal computer (see for more recent statistics, SCP, 2002).

The data stems from the 1995 wave of the 'Tijdsbestedingsonderzoek' (Time Use Survey), a survey among 3227 individuals, representative for the Dutch population above the age of 12 . First, a sample of households has been a-selectively chosen and asked to participate by phone or letter. In a second 
phase, the individuals were randomly chosen from each household. Our sample is a subset of the total database $(\mathrm{N}=3197)$ after removing missing values. The individuals were supposed to record in a diary their two main activities each quarter of an hour during a whole week, including paid work at home and out-of-home. About $6 \%$ of the total sample report that they are free-lancers and a very small percentage $(<1 \%)$ report being self-employed. $53 \%$ are in the possession of a home computer (so it seems that households with computers are slightly over represented compared to the national average), and $13 \%$ are in the possession of a modem. $4 \%$ of the individuals report that they have an internet connection at home.

Table 1 provides a more detailed look into the distribution of personal computer, modem, and internet connection possession. Table 1 shows the differences in personal computer ownership between various groups of household heads. Firstly, females have a slightly lower propensity of owning a computer, modem or internet connection. Secondly, people with a higher education have a higher chance of owning a modem and to be active on the internet. Furthermore, having a higher income also induces people to have a higher propensity to own a personal computer, modem or internet account. Therefore, ICT appliances can be characterized as luxury goods, although the small number of observations compels us to be cautious.

As Table 2 shows, those people who work more at home, have a higher chance of owning a modem and to be active on the internet. However, those individuals who work mainly at home (more than 24 hours per week) start using less ICT appliances. Probably, this last category mainly includes workers who only work at home and do not need to communicate with their workspace. Table 2 indicates a significant positive correlation between working at home and possession of ICT appliances. However, a multivariate analysis is needed to investigate the correctness of this hypothesis.

Table 2: Relation between Possession of ICT related appliances and working at home (\%) (Netherlands, 1995).

\begin{tabular}{rccc}
\hline \multicolumn{1}{c}{$\begin{array}{c}\text { Hours worked } \\
\text { at home per week }\end{array}$} & $\begin{array}{c}\text { possession of } \\
\text { a computer }\end{array}$ & $\begin{array}{c}\text { possession } \\
\text { of a modem }\end{array}$ & $\begin{array}{c}\text { possession of an } \\
\text { internet connection }\end{array}$ \\
0 & 50.8 & 11.4 & 3.1 \\
$1-8$ & 64.0 & 32.0 & 5.0 \\
$9-16$ & 71.2 & 28.8 & 8.2 \\
$17-24$ & 82.9 & 44.1 & 40.0 \\
$>24$ & 66.7 & 31.6 & 37.1 \\
\hline \hline
\end{tabular}

Source: SCP, 1995.

To understand the relation between working at home and out-of-home over an average working day, figure 1 presents the percentages of the Dutch population working at home, out-of-home, and the time spent to travelling (for all purposes) per quarter of an hour.

[INSERT FIGURE 1 HERE] 
Figure 1 clearly shows that the time spent to travelling is still dominated by commuting, as can be concluded from the two peaks at $8 \mathrm{am}$. and $5 \mathrm{pm}$. Moreover, working at home is highly dominated by working out-of-home. Only up to two percent of the total sample report working at home. Note, that this is still in line with the $3.7 \%$ of the labor force as reported by the Ministry of Transport, Public Works and Water Management. In the evening hours the percentage of working at home converges to that of working outside home, due to those people who continue to work at home after leaving the office. Noteworthy are also the coffeebreaks at $10 \mathrm{am}$. and 3 pm., and the sharp lunch break between 12 am. and $1 \mathrm{pm}$. for out-of-home workers. To a lesser extent, this behavior can also be observed for at home working, where there are busts in the distribution at $12 \mathrm{am}$. and $6 \mathrm{pm}$., representing respectively lunch time and dinner time.

In order to gain a better insight in the relations between the location of the working place and the possession of telecommunication goods, the following section will deal with a joint analysis of at home and out-of-home labor supply.

\section{A Correlated System of at Home and Out-of-home Labor Sup- ply}

Most likely, the number of hours working at home is related with the number of hours working out-ofhome. There are two opposite hypotheses. Firstly, a working day has a rather fixed number of hours in which one is able to work. Obviously, the amount of time working in an office can not be used to work at home. On the other hand, people who work much out-of-home may also be likely to have a higher number of working hours at home, due to unobserved characteristics regarding for example work attitude. Probably, individual preferences towards labor income and leisure time will play a role here. In Figure 2 working at home and working out-of-home are plotted against each other..

\section{[INSERT FIGURE 2 HERE]}

Figure 2 clearly shows a statistically significant negative correlation between working at home and outof-home. However, the relation is not very strong. A person who works an hour more out-of-home, works only 97 seconds less at home. A possible explanation could be that those who work in the Netherlands do not work much at home, as has been shown in figure 1. The Dutch work on average slightly less than 1.5 hours at home per week. This all points to a weak substitution effect between at home and out-of-home labor supply. Note also the many observations in figure 2 positioned at the horizontal and vertical axis. This means that a substantial amount of people only work at home or out-of-home, instead of a combination of both.

In order to gain some more insight into the determinants of working inside or outside one's home we develop a model where at home and out-of-home labor supply are simultaneously analyzed. First, denote $y_{i}^{*}$ as the desired amount of time spent to work. Then a simple model would look like (cf. Greene, 1992): 


$$
y_{i}^{*}=\boldsymbol{\beta}^{\prime} \mathbf{x}_{i}+\delta \omega_{i}+\varepsilon_{i}
$$

where $(\boldsymbol{\beta}, \boldsymbol{\delta})$ is a vector of parameters, $\mathbf{x}_{i}$ the personal characteristics of individual $i, \omega_{i}$ the offered market wage for individual $i$ and $\varepsilon_{i}$ a draw from an independent and identically distributed (i.i.d.) error term. The regression coefficients in (1) depend on the fact whether individuals actually participate in the labor market (see also Heckman, 1979). ${ }^{3}$ In fact, this decision identifies whether the individual's market wage is larger or equal to his or her reservation wage. Namely, if the reservation wage is larger than the market wage, then the productivity of other activities (for example household work) is always higher. ${ }^{4}$ Such a participation decision can then be denoted as:

$$
\begin{aligned}
\omega_{i}-R_{i} & =\gamma^{\prime} w_{i}+\mu_{i}, \\
z_{i} & =\left\{\begin{array}{lll}
1 & \text { if } & \omega_{i}-R_{i} \geq 0 \\
0 & & \text { otherswise }
\end{array}\right.
\end{aligned}
$$

Here, $\gamma$ is a vector of parameters, $w_{i}$ the personal characteristics of $i$ that determine whether $i$ participates in the labor market or not and $\mu_{i}$ a draw from an i.i.d. error term. $z_{i}$ is here the observed variable, $R_{i}$ is the reservation wage of individual $i$ and $\omega_{i}$ is defined as above. If $\omega_{i}-R_{i} \geq 0$, then the individual decides to participate in the labor market and $z_{i}$ is equal to 1 . Otherwise the observed variable is zero. Assuming that $\delta \neq 0$, a correlation between $(\varepsilon, \mu)$ causes a selection bias when not accounted for (Pencavel, 1986). To correct for a possible correlation between $\varepsilon_{i}$ and $\mu_{i}$, we assume $\varepsilon_{i}$ and $\mu_{i}$ to have the following bivariate distribution:

$$
\left(\varepsilon_{i}, u_{i}\right) \sim \text { bivariate normal }\left[0,0, \sigma_{\varepsilon}^{2}, 1, \rho_{\varepsilon u}\right]
$$

So the variance of the participation decision is assumed to be equal to 1 .

Assume that individual $i$ is able to spend his desired amount of time spent to work $\left(y_{i}^{*}\right)$ on both out-of-home $\left(y_{1 i}^{*}\right)$ and at home work $\left(y_{2 i}^{*}\right)$, so $y_{i}^{*}=y_{1 i}^{*}+y_{2 i}^{*}$. In this case, it depends on the costs of labor supply $y_{1 i}^{*}$ and $y_{2 i}^{*}$ whether individuals work at home or out-of-home. These costs do not only include commuting costs, but also office costs, communication costs, information costs, etcetera. The timing here is crucial. First, individual $i$ compares the reservation wage $R_{i}$ with the offered market wage $\omega_{i}$ in order to decide to work or not. Thereafter, individual $i$ decides upon the time spent to out-of-home work $\left(y_{1 i}^{*}\right)$

\footnotetext{
${ }^{3}$ Naturally, this is true when individuals are able to freely adjust their labor-supply, which seems to apply better to the female labor population (Heckman, 1974; Renes, 1992; Killingsworth and Heckman, 1986). Involuntary unemployment (e.g. among males) could prohibit such a participation decision. However, unemployment individuals will most likely systematically differ from employed individuals in education level, age, experience levels and so forth.

${ }^{4}$ This applies especially to the female labor force, which appears to be more elastic between household and paid work than the male labor force (Killingsworth and Heckman, 1986). Moreover, there is a larger occurrence of nonstructural unemployment among the male labor force participation, such as search unemployment and wait unemployment. We will return to these issues below.
} 
and to at home work $\left(y_{2 i}^{*}\right)$, conditional of course upon the costs of both types of labor supply and the time spent to at home labor supply and out-of-home labor supply, respectively. This means that for a given job and person, the reservation wages and the wage rates are the same for at home and out-of-home labor supply. Such a wage structure especially applies to individuals who accepted a job first and decided in a later stage to telecommute one or two days a week within the same job.

As Figure 2 has already shown, not all individuals in the sample work both at home and out-of-home. On the contrary, one of the two types of labor supply is usually zero. Moreover, both types of labor supply have a positive probability of being zero together. The latter is caused by the small observation period of the individuals (a week). Thus, individuals may not have worked at all due to sickness, holidays, sabbatical leaves, etcetera. Therefore, both $y_{1 i}^{*}$ and $y_{2 i}^{*}$ are censored. Allowing for a correlation between $y_{1 i}^{*}$ and $y_{2 i}^{*}$ leaves us then with a bivariate Tobit model (Maddala, 1983):

$$
\begin{aligned}
& y_{1 i}^{*}=\mathbf{x}_{i} \beta_{1}+\delta_{1} \omega_{i}+\xi_{1} \vartheta_{i}+\varepsilon_{1 i}, \\
& y_{2 i}^{*}=\mathbf{x}_{i} \beta_{2}+\delta_{2} \omega_{i}+\xi_{2} \vartheta_{i}+\varepsilon_{2 i} \text {, } \\
& y_{1 i}=\left\{\begin{array}{ccc}
y_{1 i}^{*} & \text { if } & y_{1 i}^{*}>0 \\
0 & & \text { otherwise }
\end{array}\right. \text {, } \\
& y_{2 i}=\left\{\begin{array}{ccc}
y_{2 i}^{*} & \text { if } & y_{2 i}^{*}>0 \\
0 & & \text { otherwise }
\end{array}\right. \text {, }
\end{aligned}
$$

with $y_{k i}^{*}(k \in\{1,2\})$ a latent variable (the desired number of working hours), $y_{k i}$ the observed variable, subscript 1 for working out-of-home and subscript 2 for working at home, $\vartheta_{i}$ reflecting the presence of ICT at home, and $\xi_{k}$ a scalar. Basically, the only addition to (1) is that we assume $\varepsilon_{1}$ and $\varepsilon_{2}$ to be correlated with $\rho_{\varepsilon_{1} \varepsilon_{2}}$. Now, each individual $i$ has a positive probability on one of the following four possibilities: in the observed week he or she worked only at home or out-of-home, he or she did not work or he or she worked both at home and out-of-home. Therefore, we distinguish the following four sets:

$$
\begin{aligned}
& S_{1}: y_{1}>0, y_{2}>0, \\
& S_{2}: y_{1}>0, y_{2} \equiv 0 \text {, } \\
& S_{3} \quad: \quad y_{1} \equiv 0, y_{2}>0 \text {, } \\
& S_{4} \quad: \quad y_{1} \equiv 0, y_{2} \equiv 0 \text {. }
\end{aligned}
$$

In addition to the bivariate Tobit model in (3), we also incorporate the selection mechanism in the form of a participation decision as denoted in (2). The joint likelihood of (3) and (2) is now determined by the product of the likelihoods of $(4 \mathrm{a}) \ldots(4 \mathrm{~d})$, given the decision to participate in the labor population. Now, denote the trivariate density of $\left(\varepsilon_{1}, \varepsilon_{2}, \mu\right)$ with $f(., .,$.$) , the density of the error term in the selection$ model with $f_{z}($.$) and the error term of the bivariate tobit model with f_{b}(.,$.$) . Hence, collecting terms will$ leave us with the following likelihood (see also Maddala, 1983, p. 206, and Amemiya, 1985, p. 385): 


$$
\begin{aligned}
L= & \prod_{z=0} \operatorname{Pr}(\omega-R<0) \prod_{z=1} f\left(\varepsilon_{1}, \varepsilon_{2}, \mu \mid \omega-R \geq 0\right) \operatorname{Pr}(\omega-R \geq 0) \\
= & \prod_{z=0} f_{z}(\mu) \prod_{z=1} f\left(\varepsilon_{1}, \varepsilon_{2}, \mu\right)=\prod_{z=0} f_{z}(\mu) \prod_{z=1} f_{z}(\mu) \prod_{z=1} f_{b}\left(\varepsilon_{1}, \varepsilon_{2} \mid \mu\right) \\
= & \prod_{z=0} f_{z}(\mu) \prod_{z=1} f_{z}(\mu) \prod_{S_{1} \mid z=1} f_{b}\left(\varepsilon_{1}, \varepsilon_{2} \mid \mu\right) \prod_{S_{2} \mid z=1} \int_{-\infty}^{-\boldsymbol{\beta}_{2}^{\prime} \mathbf{x}_{2}} f_{b}\left(\varepsilon_{1}, \varepsilon_{2} \mid \mu\right) d \varepsilon_{2} \\
& \prod_{S_{3} \mid z=1} \int_{-\infty}^{-\boldsymbol{\beta}_{1}^{\prime} \mathbf{x}_{1}} f_{b}\left(\varepsilon_{1}, \varepsilon_{2} \mid \mu\right) d \varepsilon_{1} \prod_{S_{4} \mid z=1} \int_{-\infty}^{-\boldsymbol{\beta}_{2}^{\prime} \mathbf{x}_{2}-\boldsymbol{\beta}_{1}^{\prime} \mathbf{x}_{1}} \int_{-\infty}^{-\infty} f_{b}\left(\varepsilon_{1}, \varepsilon_{2} \mid \mu\right) d \varepsilon_{1} d \varepsilon_{2}
\end{aligned}
$$

with parameter vector $\theta=\left(\beta_{1}, \beta_{2}, \delta_{1}, \delta_{2}, \gamma, \xi_{1}, \xi_{2}, \sigma_{1}^{2}, \sigma_{2}^{2}, \rho_{\varepsilon_{1} \varepsilon_{2}}, \rho_{\varepsilon_{1} \mu}, \rho_{\varepsilon_{2} \mu}\right)$. As can be seen in (5), due to the assumption of normality of the error terms, each of the subsets $S_{i}$ can now be rewritten as the product of two conditional normal density or distribution functions (using Bayes' rule). ${ }^{5}$ The appendix provides a more detailed (concentrated) log likelihood.

The structure of (5) resembles the Double Hurdle or zero-inflated models originally proposed by Gragg (1971) and further developed by Blundell et al. (1987) and Blundell and Meghir (1987). However, the Double Hurdle model is fundamentally different. Namely, it assumes an additional probability of the observation being zero. In other words, there are two populations. The first population always displays a zero observation, while the second population shows a zero or a positive value, hence the name zeroinflated models. In our case, we do not have to estimate another probability of being zero, because we observe whether individuals work or not.

Our model is more closely related to another set of models, which - rather confusingly - are also called hurdle models and where the outcomes are generated from a sequential decision making process. Yoshida and Guariglia (2002) estimate such a hurdle model with a bivariate Tobit structure. The main difference between the model Yoshida and Guariglia use and (5) is that we explicitly allow for a correlation between the decision to participate and the number of hours individuals decide to work. In contrast to what is usual in the literature, the Tobit structure in (5) originates from the division of labor between at home and out-of-home and the small spell of observation time, instead of the decision not to participate in the labor market. Normally, the comparison between market wages and reservation wages causes a Tobit structure, whereafter one may correct for small observations spells, misreporting, etcetera.

Labor supply can still be underestimated by (5). Namely, those who are willing to work could be failing in finding a suitable job. A possible method to correct for this is the incorporation of an additional probability measure or model in the participation decision (see for example Maki and Nishiyama, 1996).

\footnotetext{
${ }^{5}$ Namely, if $\varepsilon_{1}$ and $\varepsilon_{2}$ are normally distributed, respectively $N\left(\mu_{1}, \sigma_{1}^{2}\right)$ and $N\left(\mu_{2}, \sigma_{2}^{2}\right)$, then

$$
\varepsilon_{1} \mid \varepsilon_{2} \sim N\left(\mu_{1}+\rho_{\varepsilon_{1} \varepsilon_{2}} \frac{\sigma_{\varepsilon_{1}}}{\sigma_{\varepsilon_{2}}}\left(\varepsilon_{2}-\mu_{2}\right), \sigma_{\varepsilon_{1}}^{2}\left(1-\rho_{\varepsilon_{1} \varepsilon_{2}}^{2}\right)\right)=\frac{1}{\sigma_{\varepsilon_{1}} \sqrt{1-\rho_{\varepsilon_{1} \varepsilon_{2}}^{2}}} \phi\left(\frac{\varepsilon_{1}-\mu_{1}-\rho_{\varepsilon_{1} \varepsilon_{2}} \frac{\sigma_{\varepsilon_{1}}}{\sigma_{\varepsilon_{2}}}\left(\varepsilon_{2}-\mu_{2}\right)}{\sigma_{\varepsilon_{1}} \sqrt{1-\rho_{\varepsilon_{1} \varepsilon_{2}}^{2}}}\right)
$$
}

Conditioning in a trivariate normal distribution is a straightforward extension (see e.g. Greene, 1992, for more details). 
Thus, individuals who are willing to work for the market wage face a probability of not finding a job. Such a structure leaves us then with a mixture of a Hurdle and a Double Hurdle model. For simplicity reasons, we omit this extension. In the next section, we first discuss the variables used in the analysis and then present the estimation results.

\section{Variables and Results}

\subsection{Variables}

In order to address the issue of telecommuting, we focus on the possession of ICT appliances, in this case possession of a modem. Obviously, a person who works at home does not need to use his modem per se. However, the definition of telecommuting as cited in the Introduction is rather broad and may even involve only a telephone. The hypothesis here is that using more advanced ICT appliances (like modems) stimulates working at home. A more fundamental problem is the possible endogeneity of modem possession and working at home or out-of-home. The point is that the decision to work at home could stimulate the purchase of a modem as well as the possibility that owning a modem could induce people to work at home. Therefore, we use an instrumental variable approach to explain the possession of a modem. Next to the usual social-economic instruments, we use working or playing with a personal computer for a hobby as an instrument. Obviously, individuals who start teleworking could purchase ICT appliances and may be induced by their presence to spend leisure time with them. However, the reverse relation is much more likely. People who like spending leisure time with ICT appliances already have both equipment and knowledge to use ICT to increase their at home labor supply. Appendix B provides the details of the binary probit regression from which we use the results to construct an (estimated) probability for each individual to possess a modem.

An important explanatory variable in the theory of labor-supply is the hourly market wage an individual faces (see e.g. Pencavel, 1986). Whether individuals work more or less when their market wage increases is a priori difficult to determine. However, empirical evidence suggest that in the long run individuals work less when the wage-rate increases. For example, from 1959 to 1995 net yearly income in the Netherlands per person or couple who received an income increased with 70\% (in 1996 prices) while the hours worked per full-time worker decreased in the same period with $22 \%{ }^{6}$ A possible explanation is that leisure time can be regarded as a luxury good and will therefore increase with the wage rate. ${ }^{7}$ Our dataset only reports net household incomes instead of individual wage rates. To estimate individual wage rates, we selected single households and divide the total net income by the contractual number of working hours. Then we carry out a loglinear wage regression on single working individuals from which we use the coefficients to construct the new wage per person variable for individuals in all types of households. Appendix $\mathrm{C}$ provides the results of the wage regression. In addition to log wages, we also incorporate a non-linear effect in the form of squared log wages in (5). That ensures that with higher wages labor

\footnotetext{
${ }^{6}$ Figures obtained from the website from the Dutch statistical office (CBS): http://statline.cbs.nl/StatWeb/.

${ }^{7}$ We refer to Becker (1965) for an extensive elaboration of why the number of working hours tend to decline with increasing wage rates.
} 
supply is able to drop (also called a backward bending effect) as discussed above.

The remainder of the socio-economic variables used in the specification are all straightforward and conform intuition. We include a dummy for being married and a categorical variable for the number of children in order to control for household characteristics. The dummy for being a female and the cross-effect of being a female with a child under 12 are used to correct for the weaker position of females on the labor market compared to males. We incorporate a categorical variable for the distance to the nearest train station and a dummy for car possession in order to incorporate the generalized costs of commuting. Finally, we correct for education, age and the type of job the individual has. The latter is incorporated as proxy for sector effects.

For the participation decision, we use the following variables: age dummies, being female, being female and having a child under the age of 12 , the urbanization level of the place of residence, having children under the age of 12, a measure for the social class of the household and the estimated wage rate. 
Table 3: Correlated tobit estimates of hours per week worked (non-farming) at home and out-of-home with sample selection (MLE; probability values between parentheses; $N=3197$ ).

\begin{tabular}{|c|c|c|c|c|c|c|}
\hline & \multicolumn{2}{|c|}{ Out-of-home } & \multicolumn{2}{|c|}{ At home } & \multicolumn{2}{|c|}{ Participation } \\
\hline & Coeff. & Prob. & Coeff. & Prob. & Coeff. & Prob \\
\hline Constant & -135.04 & 0.00 & -80.27 & 0.00 & -2.82 & 0.00 \\
\hline Possession of a modem & 4.53 & 0.09 & 13.86 & 0.00 & & \\
\hline Dummy Female & -6.77 & 0.00 & 0.76 & 0.28 & -0.29 & 0.00 \\
\hline Dummy married & -1.88 & 0.00 & -0.89 & 0.18 & 0.04 & 0.23 \\
\hline Female $*$ children $<12$ & -7.40 & 0.00 & 2.36 & 0.09 & -0.60 & 0.00 \\
\hline Distance to nearest train station & -0.65 & 0.03 & 0.01 & 0.49 & & \\
\hline In possession of a car & 1.30 & 0.07 & 1.54 & 0.13 & & \\
\hline Urbanization level & & & & & -0.04 & 0.00 \\
\hline Social Class & & & & & -0.09 & 0.00 \\
\hline ln(hourly wage) & 156.89 & 0.00 & 43.43 & 0.08 & 2.09 & 0.00 \\
\hline $\ln$ (hourly wage) squared & -38.68 & 0.00 & -2.56 & 0.37 & & \\
\hline \multicolumn{7}{|l|}{ Occupation dummies (unedu. bl. collar) } \\
\hline High skilled white collar & -0.25 & 0.43 & 2.43 & 0.08 & & \\
\hline Medium skilled white collar & 2.78 & 0.00 & -2.06 & 0.05 & & \\
\hline Low skilled white collar & 2.15 & 0.01 & -0.69 & 0.30 & & \\
\hline Educated blue collar & 3.84 & 0.00 & 1.38 & 0.19 & & \\
\hline Self employed/free-lance & -2.91 & 0.01 & 13.04 & 0.00 & & \\
\hline \multicolumn{7}{|l|}{ Education dummies (basic) } \\
\hline Lower vocational & 10.16 & 0.00 & -1.06 & 0.30 & & \\
\hline Medium vocational & 7.94 & 0.00 & -5.14 & 0.02 & & \\
\hline Craft education & 9.52 & 000 & -5.59 & 0.01 & & \\
\hline High vocational & 9.02 & 0.00 & -5.25 & 0.03 & & \\
\hline College & 9.57 & 0.00 & -0.65 & 0.39 & & \\
\hline University & 10.82 & 0.00 & -1.00 & 0.37 & & \\
\hline \multicolumn{7}{|l|}{ Age dummies (<20 years) } \\
\hline $20-30$ years & -2.12 & 0.22 & -9.84 & 0.02 & 0.78 & 0.00 \\
\hline $30-40$ years & -3.84 & 0.10 & -12.84 & 0.00 & 0.44 & 0.00 \\
\hline $40-50$ years & -2.87 & 0.16 & -14.68 & 0.00 & -0.08 & 0.32 \\
\hline $50-60$ years & -3.11 & 0.12 & -14.35 & 0.00 & -0.93 & 0.00 \\
\hline$>60$ years & & & & & -2.58 & 0.00 \\
\hline$\sigma_{\varepsilon_{i}}$ & 13.91 & 0.00 & 13.06 & 0.00 & & \\
\hline$\rho_{\varepsilon_{i} \mu}$ & -0.22 & 0.11 & -0.12 & 0.34 & & \\
\hline$\rho_{\varepsilon_{1} \varepsilon_{2}}$ & & & -0.03 & 0.40 & & \\
\hline Log Likelihood & & & & & & -1901.96 \\
\hline Pseudo- $R^{2}$ & & & & & & 0.39 \\
\hline
\end{tabular}

Note: The Pseudo- $R^{2}$ is defined as: $1-\frac{\ln L}{\ln L_{0}}$, where $L_{0}$ is the likelihood of the restricted model. 
The dummies for having a child under 12 and being a female are incorporated to correct for the fact that females tend to spend more time to child care then males. The following subsection gives the results.

\subsection{Results}

Tables 3 presents the maximum likelihood estimates from the log likelihood as denoted in (5). We consider the non-farming labor force, where labor supply is taken over the whole week. For comparison, Table D.1 in Appendix D also presents the maximum likelihood estimates for the labor supply during office hours.

Table 3 shows that the substitution hypothesis of at home and out-of-home labor supply over the whole week is not supported ( $\rho_{\varepsilon_{1} \varepsilon_{2}}$ is close to zero), although there is a substitution effect for labor supply during office hours (see Appendix D). The main result is that modem possession increases latent at home labor supply with almost 14 hours when measured across the whole week. In addition, possession of a modem also increases latent out-of-home labor supply with 4.5 hours. Given the censoring, these marginal effects reduces to 4.08 and 2.57 hours, respectively. Note that the increase in at home labor supply is remarkable due to the relatively low level of actual at home labor supply. ${ }^{8}$ Moreover, being in possession of a modem is for at home labor supply the only significant variable (except for the control dummies), indicating the relative importance of ICT appliances opposite to socioeconomic variables.

For out-of-home labor supply, especially the female dummy and the cross-effect between females and having children younger than 12 are significant and sizeable, reflecting the still common division of tasks in households in the Netherlands. Commuting costs seem to be especially important for out-of-home labor supply and not significant for at home labor supply, although the possession seems to increase at home labor supply marginally. The control dummies indicate that the propensity of working at home is increasing with education and decreasing with age, whereas out-of-home work does not display an obvious structure for age and education level.

The coefficients determining the participation decision are mainly intuitive and significant. Being female, having children younger than 12 years and being in a low social class ${ }^{9}$ lowers the propensity of being active on the labor market, which is conform intuition. The age dummies display a negative relation between age and participation. The higher the age, the less active individuals are on the labor market. After the age of 60 this probability is declining very rapidly. Moreover, the higher the estimated hourly wage is, the higher is the propensity to work. Wage is compared here to the reservation wage and confirms theory that below a certain wage level individuals stop supplying labor because of opportunity costs of for example household activities.

\footnotetext{
${ }^{8}$ It is also possible to use a personal computer or an internet account dummy instead of a modem dummy. The two ICT coefficients have the same sign for both the personal computer dummy and the internet account dummy. Moreover, cf. intuition, the personal computer dummy has a lower impact than the modem dummy and the internet account dummy a higher impact. If we have to extrapolate these results to the current situation, then a broadband connection may even have a higher impact on at home labor supply. At least it is clear that the more sophisticated the ICT appliance is, the higher the impact. However, whether this should be regarded relative to the other ICT appliances in the same period or whether this is an absolute process over time remains an issue for further research.

${ }^{9}$ The social class variable (derived from a combination of house-ownership, educational attainment and income) is an interval variable from 1 till 5 , where 1 is the highest social class and 5 the lowest.
} 
The coefficients of the wage rates for labor supply are intuitively appealing. Figure 3 depicts the simulated relation between wage rate and labor supply for married high skilled white collar male workers, with university education and between 30 and 40 years (all other dummies and variables in Table 2 are set at zero).

\section{[INSERT FIGURE 3 HERE]}

Clearly, the impact of wage on out-of-home labor supply is much larger. However, there is a backbending effect in this relation. After approximately a net wage rate of 8 Euro per hour, people tend to supply less out-of-home labor for an increased wage rate. In our sample, the mean observed wage rate is about 8.03 Euro per hour, which means that the majority of the workers is around the out-of-home supply maximum. At home labor supply does not suffer from such a back-bending effect (at least for realistic hourly wage rates). Namely, from approximately 8 Euro per hours labor supply people tend to supply at home labor, which eventually surpasses out-of-home labor supply (at an estimated wage rate of about 14 Euro). A theoretical justification for this result may be that out-of-home labor supply suffers from commuting costs. At a certain wage level, indirect costs of commuting time will simply be too high to sustain out-of-home labor supply. This is especially true with private transport (i.e. car). Although out-of-home labor supply decreases after a certain threshold, total labor supply will eventually increase due to the increase in at home labor supply. As figure 1 already shows, at home labor supply is still a marginal phenomenon compared to out-of-home labor supply. In addition, it appears to be decreasing with age. For example, at home labor supply for the age group between 50 and 60 starts at a higher hourly wage rate, which can be estimated at around 8.5 Euro. If we do not allow for modem possession, then both supply curves in Figure 3 will shift to the right. However, the effect is particularly strong for at home labor supply, where people start working at home at 12.5 Euro per hour. In addition, the omission of modem possession also causes total labor supply to decrease to less than 30 hours per week.

In the labor supply literature (see for example Killingsworth and Heckman, 1986), the difference between female and male labor supply has often been stressed. In economic terms, females are supposed to have a comparative advantage in household productivity. To investigate to what extent these differences are still present, we split our sample in a male and a female part. ${ }^{10}$ Interestingly, males and females do not have a fundamental different labor market supply. Their coefficients for the participation decision are almost similar and the labor supply coefficients do not change qualitatively (in sign of significance level).

However, considerable differences exist between male and female supply regarding the impact of the modem coefficients and the correlation between at home and out-of-home labor supply (see also Mokhtarian et al., 1998, for gender differences towards teleworking). In addition to these differences, the timing of labor supply seems to have another crucial influence on the modem coefficients and the correlation between the two types of labor supply. Therefore, we examine the marginal effects of these coefficients (given the censoring) further along two lines: namely, the difference between the male and female labor force and the differences between labor supply during office hours and non-office hours.

\footnotetext{
${ }^{10}$ We have not included the results of these estimations in this paper. Results are available from the corresponding author upon request.
} 
Table 4: Marginal effects of the modem coefficients (given the censoring)

and correlation for different samples (significant at $5 \%$ level in bold)

\begin{tabular}{rrrr}
\hline \hline Samples & $\begin{array}{c}\text { Modem coefficient } \\
\text { out-of-home }\end{array}$ & $\begin{array}{c}\text { Modem coefficient } \\
\text { at home }\end{array}$ & $\begin{array}{c}\text { Correlation at home and } \\
\text { out-of-home }\left(\rho_{\varepsilon_{1} \varepsilon_{2}}\right)\end{array}$ \\
\hline Total labor force & & & -0.03 \\
Total & 4.08 & $\mathbf{2 . 5 7}$ & $\mathbf{0 . 2 3}$ \\
Office hours & $\mathbf{7 . 9 1}$ & $\mathbf{0 . 9 2}$ & 0.13 \\
Non-office hours & $\mathbf{- 3 . 6 4}$ & $\mathbf{1 . 5 4}$ & -0.25 \\
Male labor force & & & $\mathbf{- 0 . 5 3}$ \\
Total & 4.07 & 2.77 & 0.06 \\
Office hours & $\mathbf{6 . 0 9}$ & 0.40 & 0.26 \\
Non-office hours & -1.84 & 1.56 & 0.19 \\
Female labor force & & & 0.26 \\
Total & 5.41 & $\mathbf{1 . 8 7}$ & $\mathbf{0 . 8 9}$ \\
Office hours & $\mathbf{9 . 6 3}$ & $\mathbf{0 . 9 6}$ & \\
Non-office hours & $\mathbf{4 . 9 0}$ & & \\
\hline \hline
\end{tabular}

Table 4 displays the marginal effects of modem possession on actual labor supply and the correlation between at home and out-of-home labor supply for several subsamples. ${ }^{11}$ All other coefficients have been omitted for reasons of clarity. However, they are comparable with those reported in Table 3. The results for the modem possession variable in Table 4 can be summarized as follows: firstly, people with ICT facilities at home tend to work more, both at home and out-of-home. So in general terms there is no sign that ICT leads to less time spent at work, on the contrary. The case for complementarity between work at the two places in view of ICT facilities at home is supported by our research. Secondly, when we only consider office hours, we observe that possession of ICT facilities at home again stimulates both at home and out-of-home labor supply. The latter effect is much larger than the former effect. Thus, owners of ICT facilities tend to have fuller work days during office hours at the work place than other people, and when they are at home during office hours, they more often are involved in work-at-home. Thirdly, outside office hours modem possession leads to less work out of home. Thus the ICT facilities stimulate people not to be at the workplace. The time worked less is partly substituted by work at home outside office hours. This implies that the overall pattern of complementarity of work at home and out-of-home due to ICT possession during office hours does not hold during the rest of the week. It is here that substitution dominates. Note, however, that labor supply during office hours dominates labor supply during the rest of the week so that for the overall pattern we find complementarity as the main feature. For transport, this has two important and rather different implications: namely, modem possession leads to (i) less work related trips in the weekends and (ii) changes in timing of commuting

\footnotetext{
${ }^{11}$ Marginal effects are calculated for actual labor supply $(y)$, instead of latent labor supply $\left(y^{*}\right)$. Therefore, the marginal effect is not $\xi_{j}$, but $\xi_{j} \Phi\left(\frac{\beta / \mathbf{x}_{i}}{\sigma_{j}}\right)$, with $\boldsymbol{\beta}$ the vector of all coefficients. Significance levels of the marginal effects are calculated using the delta method (Greene, 1993).
} 
trips during weekdays resulting in earlier return trips; this may aggravate afternoon peak congestion. Finally, during office hours modem possession has a larger impact on women compared with men as far as at home work is concerned. The marginal effect of ICT possession is two times as high for at home labor supply of females during office hours than for the at home labor supply of males. Therefore, males seem to be less elastic between out-of-home and at home labor supply during office hours. With respect to non-office hours and especially work overall, however, modem possession has a larger impact on men than on women for at-home work.

The correlation coefficient displays a similar pattern across the gender groups. During office hours and overall, at home and out-of-home work are negatively correlated, especially for the male labor force. However, outside office hours this hypothesis does not hold anymore and there is even some (weak) evidence for a positive relation between out-of-home and at home labor. The following section will sum up the main conclusions and offer some directions for further research.

\section{Conclusions \& Further Research}

Although the impact of ICT on the Dutch labor market appears to be rather large, teleworking in the Netherlands is still a marginal phenomenon. However, with the ongoing decrease in the costs of ICT appliances and services, the further increase in the flexibilisation of the Dutch labor force and the increasing adoption of ICT, figures for teleworking are expected to increase. In order to understand the determinants of teleworking and the possible effects they may have, this paper analyzes the effect of ICT facilities within the household on both at home and out-of-home labor supply. First of all, it appears that at home labor supply is rather low in the Netherlands. Second, possession of a modem leads to an increase of both at home and out-of-home labor supply. Actual at home labor supply during office hours is increased with about an hour when workers are in possession of a modem. In addition, the possession of a modem increases total at home labor supply with more than 2.5 hours per week. Modem possession also increases out-of-home labor supply and the effect is larger in absolute terms. However, effects on at home work may be considered as larger in relative terms given the very low average level of at home labor supply. Moreover, during office hours the availability of ICT seems to have a higher influence on the female than on the male labor force, indicating that females appreciate a higher degree of flexibility more than males.

Typically, higher educated and younger individuals work more at home. In addition, the higher the wage rate is, the smaller out-of-home labor supply and the larger at home labor supply. According to the microeconomic framework, costs of out-of-home labor supply (commuting costs, less flexibility, etc.) eventually outweigh wages, whereas at home labor supply becomes more attractive at higher wages. This results in a non-concave labor supply function (see Fig. 3).

Policy measures have been directed to promote teleworking in order to tackle congestion problems. However, subsidizing ICT appliances for households does not seem to be the appropriate measure. Individuals do work more at home due to ICT, but mostly during non-office hours (weekends and evenings). ICT facilitates more flexible working hours - which seems especially attractive to the female labor force 
-, so that traffic peaks could be topped off and spread more evenly across the day. But we found also a possible reverse effect: people may avoid overtime work at the job location and return home to continue work at home during the (early) evening. This may cause an increase in the afternoon peak-congestion. Therefore, further research into the trade-off between ICT use and commuting with special attention to the timing issue is warranted.

\section{Acknowledgement}

This research has been made possible by a research grant from the NWO Incentive Program Environment and Economics, nr. 014-45-204-P. The authors would like to thank Jos van Ommeren, Jan Rouwendal, and three anonymous referees for helpful remarks.

\section{References}

[1] Amemiya, T., 1985 Advanced Econometrics (Basil Blackwell Ltd, Oxford)

[2] Becker, G.S., 1965, "A Theory of the Allocation of Time" The Economic Journal 75 493-517

[3] Bélanger, F., 1998, "Workers' Propensity to Telecommute: An Empirical Study" Information $\mathcal{E}$ Management 35 139-153

[4] Blundell, R. and C. Meghir, 1987, "Bivariate Alternatives to the Tobit Model" Journal of Econometrics 34 197-200

[5] Blundell, R., J. Ham and C. Meghir, 1987, "Unemployment and Female Labor Supply" The Economic Journal 97 44-64

[6] Cragg, J.G., 1971, "Some Statistical Models for Limited Dependent Variables with Application to the Demand for Durable Goods" Econometrica 39 829-844

[7] CBS, 1997 Statistisch Jaarboek (Centraal Bureau voor de Statistiek, Voorburg/Heerlen)

[8] DeSanctis, G., 1984, "Attitudes Toward Telecommuting: Implications for Work-at-home Programs" Information \&3 Management 7 133-139

[9] Fortuijn, J.D., 1993, Een Druk Bestaan: Tijdsbesteding en Ruimtegebruik van Tweeverdieners met Kinderen (Sociaal Wetenschappelijke Studies, Ph.D. Dissertation, Amsterdam)

[10] Greene, W.H., 1993 Econometric Analysis (MacMillan Publishing Company, New York)

[11] Heckman, J., 1974, "Shadow Prices, Market Wages, and Labor Supply" Econometrica 42 679-694

[12] Heckman, J., 1979, "Sample Selection Bias as a Specification Error" Econometrica 47 153-161

[13] Hjorthol, R.J., 2002, "The Relation between Daily Travel and Use of the Home Computer" Transportation Research A 36 437-452 
[14] Killingsworth, M.R. and J. Heckman, 1986, "Female Labor Supply: A Survey", in Handbook of Labor Economics Eds O.C. Ashenfelter, R. Layard (North-Holland, Amsterdam) 103-203

[15] Maddala, G.S., 1983 Limited Dependent and Qualitative Variables in Econometrics (Cambridge University Press, Cambridge)

[16] Maki, A. and S. Nishiyama, 1996, "An Analysis of Under-reporting for Micro-data sets: The Misreporting or Double-Hurdle Model" Economics Letters 52 211-220

[17] Ministerie van Verkeer en Waterstaat, 2001 Verkeersgegevens: Jaarrapport 1999 (Van de Ridder b.v., Nijkerk)

[18] Mokhtarian, P., 1998, "A Synthetic Approach to Estimating the Impacts of Telecommuting on Travel Urban Studies 35 215-241

[19] Mokhtarian, P., M.N. Bagley, and I. Solomon, 1998, "The impact of Gender, Occupation, and Presence of Children on Telecommuting Motivations and Constraints" Journal of the American Society for Information Science 49 1115-1134

[20] Mokhtarian, P. and I. Salomon, 1996a, "Modeling the Choice of Telecommuting: 2. A case of the preferred impossible alternative" Environment and Planning A 28 1859-1876

[21] Mokhtarian, P. and I. Salomon, 1996b, "Modeling the Choice of Telecommuting: 3. Identifying the choice set and estimating binary choice models for technology-based alternatives" Environment and Planning A 28 1877-1894

[22] Olson, M.N., 1983, "Remove Office Work: Changing Work Patterns in Space and Time" Communications of the ACM $\mathbf{2 6}$ 182-187

[23] Pencavel, J., 1986, "Labor Supply of Men: A Survey", in Handbook of Labor Economics Eds O.C. Ashenfelter, R. Layard (North-Holland, Amsterdam) 3-102

[24] Renes, G., 1991 Working Women; Their Preferences and their Constraints (dissertation, Leiden)

[25] Salomon, I., 2000, "Can Telecommunications Help Solve Transportation Problems?", in Handbook of Transportation Modelling Eds D.A. Hensher, K.J. Button (Pergamon Press, Oxford) pp 449-462

[26] SCP, 1996 Tijdsbestedingsonderzoek (Sociaal en Cultureel Planbureau, Den Haag)

[27] SCP, 2002, E-cultuur: Een Empirische Verkenning (Sociaal en Cultureel Planbureau, Den Haag)

[28] Vilhelmson, B. and E. Thulin, 2001, "Is Regular Work at Fixed Places Fading Away? The Development of ICT-based and Travel-based Modes of Work in Sweden" Environment and Planning A 33 $1015-1029$

[29] Yamamoto, T. and R. Kitamura, 1999, "An analysis of Time Allocation to at home and Out-of-home Discretionary Activities Across Working Days and Non-working Days" Transportation, 26 211-230 
[30] Yap, C.S. and H. Tng, 1990, "Factors Associated with Attitudes Towards Telecommuting" Information $\mathcal{E}$ Management 19 227-235

[31] Yen, J., 2000, "Interpreting Employee Telecommuting Adoption: An Economics Perspective" Transportation 27 149-164

[32] Yoshida, A. and A. Guariglia, 2002, "Estimating Saving Functions in the Presence of Excessive-zeros Problems" Econometrics Journal 5 435-456 


\section{A The Log Likelihood}

Before presenting the log likelihood we first have to construct the following submatrices from the variancecovariance matrix from the trivariate distribution function $f\left(\varepsilon_{1}, \varepsilon_{2}, \mu\right)$ :

$$
\Sigma_{\varepsilon_{1}}=\left[\begin{array}{c}
\sigma_{\varepsilon_{1} \varepsilon_{2}} \\
\sigma_{\varepsilon_{1} \mu}
\end{array}\right], \Sigma_{\varepsilon_{2}}=\left[\begin{array}{c}
\sigma_{\varepsilon_{1} \varepsilon_{2}} \\
\sigma_{\varepsilon_{2} \mu}
\end{array}\right], \Sigma_{\varepsilon_{1} \varepsilon_{1}}=\left[\begin{array}{cc}
\sigma_{\varepsilon_{2}}^{2} & \sigma_{\varepsilon_{2} \mu} \\
\sigma_{\varepsilon_{2} \mu} & 1
\end{array}\right], \Sigma_{\varepsilon_{2} \varepsilon_{2}}=\left[\begin{array}{cc}
\sigma_{\varepsilon_{1}}^{2} & \sigma_{\varepsilon_{1} \mu} \\
\sigma_{\varepsilon_{1} \mu} & 1
\end{array}\right]
$$

where $\sigma_{\varepsilon_{1} \varepsilon_{2}}$ is the covariance between $\varepsilon_{1}$ and $\varepsilon_{2}$. After basic manipulations with the normal distribution function, the (concentrated) log likelihood then amounts to:

$$
\begin{aligned}
& \log L=\sum_{i}\left(1-z_{i}\right) \log \Phi\left(-\gamma^{\prime} w_{i}\right)+\sum_{i} z_{i} \log \left(1-\Phi\left(-\gamma^{\prime} w_{i}\right)\right)+
\end{aligned}
$$

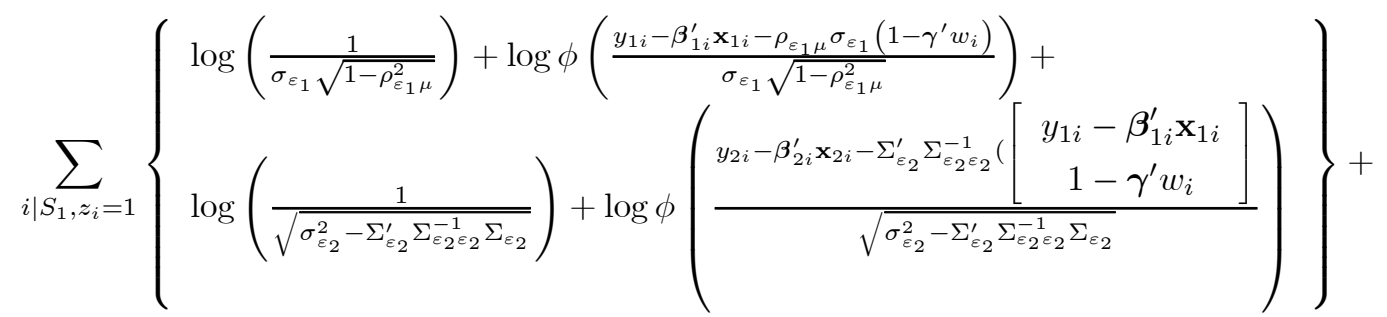

$$
\begin{aligned}
& \sum_{i \mid S_{2}, z_{i}=1}\left\{\begin{array}{c}
\log \left(\frac{1}{\sigma_{\varepsilon_{1}} \sqrt{1-\rho_{\varepsilon_{1} \mu}^{2}}}\right)+\log \phi\left(\frac{y_{1 i}-\boldsymbol{\beta}_{1 i}^{\prime} \mathbf{x}_{1 i}-\rho_{\varepsilon_{1} \mu} \sigma_{\varepsilon_{1}}\left(1-\gamma^{\prime} w_{i}\right)}{\sigma_{\varepsilon_{1}} \sqrt{1-\rho_{\varepsilon_{1} \mu}^{2}}}\right)+ \\
\log \Phi\left(\frac{-\boldsymbol{\beta}_{2 i}^{\prime} \mathbf{x}_{2 i}-\Sigma_{\varepsilon_{2}}^{\prime} \Sigma_{\varepsilon_{2} \varepsilon_{2}}^{-1}\left(\left[\begin{array}{c}
y_{1 i}-\boldsymbol{\beta}_{1 i}^{\prime} \mathbf{x}_{1 i} \\
1-\gamma^{\prime} w_{i}
\end{array}\right]\right.}{\sqrt{\sigma_{\varepsilon_{2}}^{2}-\Sigma_{\varepsilon_{2}}^{\prime} \Sigma_{\varepsilon_{2} \varepsilon_{2}}^{-1} \Sigma_{\varepsilon_{2}}}}\right)
\end{array}\right\}+ \\
& \sum_{i \mid S_{3}, z_{i}=1}\left\{\begin{array}{c}
\log \left(\frac{1}{\sigma_{\varepsilon_{2}} \sqrt{1-\rho_{\varepsilon_{2} \mu}^{2}}}\right)+\log \phi\left(\frac{y_{2 i}-\boldsymbol{\beta}_{2 i}^{\prime} \mathbf{x}_{2 i}-\rho_{\varepsilon_{2} \mu} \sigma_{\varepsilon_{2}}\left(1-\gamma^{\prime} w_{i}\right)}{\sigma_{\varepsilon_{2}} \sqrt{1-\rho_{\varepsilon_{2} \mu}^{2}}}\right)+ \\
\log \Phi\left(\frac{-\boldsymbol{\beta}_{1 i}^{\prime} \mathbf{x}_{1 i}-\Sigma_{\varepsilon_{1}}^{\prime} \Sigma_{\varepsilon_{1} \varepsilon_{1}}^{-1}\left(\left[\begin{array}{c}
y_{2 i}-\boldsymbol{\beta}_{2 i}^{\prime} \mathbf{x}_{2 i} \\
1-\gamma^{\prime} w_{i}
\end{array}\right]\right.}{\sqrt{\sigma_{\varepsilon_{1}}^{2}-\Sigma_{\varepsilon_{1}}^{\prime} \Sigma_{\varepsilon_{1} \varepsilon_{1}}^{-1} \Sigma_{\varepsilon_{1}}}}\right)
\end{array}\right\}+ \\
& \sum_{i \mid S_{4}, z_{i}=1}\left\{\log \Phi_{2}\left(\begin{array}{c}
\frac{y_{1 i}-\beta_{1 i}^{\prime} \mathbf{x}_{1 i}-\rho_{\varepsilon_{1} \mu} \sigma_{\varepsilon_{1}}\left(1-\gamma^{\prime} w_{i}\right)}{\sigma_{\varepsilon_{1}} \sqrt{1-\rho_{\varepsilon_{1} \mu}^{2}}}, \frac{y_{2 i}-\beta_{2 i}^{\prime} \mathbf{x}_{2 i}-\rho_{\varepsilon_{2} \mu} \sigma_{\varepsilon_{2}}\left(1-\gamma^{\prime} w_{i}\right)}{\sigma_{\varepsilon_{2}} \sqrt{1-\rho_{\varepsilon_{2} \mu}^{2}}}, \\
\frac{\rho_{\varepsilon_{1_{2}} \varepsilon_{2}} \sigma_{\varepsilon_{1}} \sigma_{\varepsilon_{2}}-\rho_{\varepsilon_{1} \mu} \sigma_{\varepsilon_{1}} \rho_{\varepsilon_{\varepsilon_{2} \mu} \sigma_{\varepsilon_{2}}}}{\sigma_{\varepsilon_{1}} \sqrt{1-\rho_{\varepsilon_{1} \mu}^{2}} \sigma_{\varepsilon_{2}} \sqrt{1-\rho_{\varepsilon_{2} \mu}^{2}}}
\end{array}\right)\right\}
\end{aligned}
$$

where $\phi$ denotes the standard normal density function, $\Phi$ the standard normal distribution function and $\Phi_{2}$ the standard bivariate normal distribution function. The first two terms in (6) represent the chance of being employed while the last four terms are the likelihood for each set $S_{j}(j=1, \ldots, 4)$ given that individual $i$ is employed. Note that we condition over $\mu$, instead of over $\left(\varepsilon_{1}, \varepsilon_{2}\right)$. The latter is intrinsically incorrect because $f\left(\varepsilon_{1}, \varepsilon_{2}\right)$ is not normally distributed due to the censoring, while on the other hand the errors terms in each subset $S_{j}$ do have a normal distribution. 


\section{B The Modem Equation}

In order to instrument the possession of a modem variable, we first carry out a bivariate probit regression on the possession of a modem. Table B.1 reports the results.

Table B.1: Maximum likelihood results of a probit regression on the possession of a modem (significant at a $5 \%$ level in bold)

\begin{tabular}{rrr}
\hline \hline & Coefficient & Standard error \\
\hline Constant & $\mathbf{- 0 . 9 4}$ & 0.18 \\
Age $(/ 100)$ & $\mathbf{- 0 . 5 2}$ & 0.22 \\
Dummy female & 0.05 & 0.06 \\
Urbanization level & 0.01 & 0.01 \\
Social class & $\mathbf{- 0 . 2 2}$ & 0.03 \\
Dummy children < 12 & $\mathbf{- 0 . 0 6}$ & 0.06 \\
Dummy employed & $\mathbf{0 . 2 5}$ & 0.07 \\
Dummy computer for a hobby & $\mathbf{0 . 6 4}$ & 0.06 \\
\hline Log Likelihood & & 1108.84 \\
Pseudo- $R^{2}$ & & 0.10 \\
$N$ & & 3197 \\
\hline \hline
\end{tabular}

Denote with $\mathbf{X}_{m}$ the matrix of exogenous variables and with $\widehat{\beta_{m}}$ the vector of estimated coefficients. Then the estimated probability of owning a model boils down to $\Phi\left(\mathbf{X}_{m} \widehat{\beta_{m}}\right)$ 


\section{The Wage Equation}

In order to obtain individual wages, we carry out a log-linear wage regression on all single person households, which have reported their wage. Table C.1 reports the regression estimates.

Table C.1: OLS results of a log-linear wage regression (significant at a $5 \%$ level in bold)

\begin{tabular}{rrr}
\hline \hline & Coefficient & Stand. error \\
\hline Constant & $\mathbf{0 . 8 2}$ & 0.23 \\
Age & $\mathbf{0 . 0 5}$ & 0.01 \\
Age-squared & $\mathbf{0 . 0 0}$ & 0.00 \\
Dummy female & $\mathbf{- 0 . 0 8}$ & 0.03 \\
Education dummies & & \\
Lower vocational & -0.01 & 0.08 \\
Medium vocational & 0.14 & 0.08 \\
Craft education & $\mathbf{0 . 1 4}$ & 0.07 \\
High vocational & $\mathbf{0 . 2 6}$ & 0.08 \\
College & $\mathbf{0 . 2 4}$ & 0.07 \\
University & $\mathbf{0 . 3 2}$ & 0.07 \\
\hline $\bar{R}^{2}$ & & 0.37 \\
$N$ & & 205 \\
\hline \hline
\end{tabular}




\section{Estimation for Office Hours}

Table D.1: Correlated tobit estimates of hours per week worked (non-farming) at home and out-of-home with sample selection (MLE; probability values between parentheses; $N=3197$ ).

\begin{tabular}{|c|c|c|c|c|c|c|}
\hline & \multicolumn{2}{|c|}{ Out-of-home } & \multicolumn{2}{|c|}{ At home } & \multicolumn{2}{|c|}{ Participation } \\
\hline & Coeff. & Prob. & Coeff. & Prob. & Coeff. & Prob \\
\hline Constant & -139.93 & 0.00 & -50.76 & 0.07 & -2.87 & 0.00 \\
\hline Possession of a modem & 9.47 & 0.00 & 9.84 & 0.01 & & \\
\hline Dummy Female & -5.14 & 0.00 & 0.17 & 0.44 & -0.28 & 0.00 \\
\hline Dummy married & -1.55 & -0.01 & 0.04 & 0.48 & 0.05 & 0.19 \\
\hline Female $^{*}$ children $<12$ & -7.86 & 0.00 & 0.63 & 0.35 & -0.60 & 0.00 \\
\hline Distance to nearest train station & -0.58 & 0.03 & 0.24 & 0.30 & & \\
\hline In possession of a car & 1.12 & 0.09 & 1.30 & 0.16 & & \\
\hline Urbanization level & & & & & -0.04 & 0.00 \\
\hline Social Class & & & & & -0.09 & 0.00 \\
\hline $\ln ($ hourly wage) & 138.68 & 0.00 & 13.87 & 0.36 & 2.11 & 0.00 \\
\hline $\ln ($ hourly wage $)$ squared & -33.79 & 0.00 & 2.16 & 0.42 & & \\
\hline \multicolumn{7}{|l|}{ Occupation dummies (unedu. bl. collar) } \\
\hline High skilled white collar & 1.82 & 0.09 & 2.21 & 0.09 & & \\
\hline Medium skilled white collar & 4.04 & 0.00 & -1.20 & 0.16 & & \\
\hline Low skilled white collar & 3.81 & 0.00 & -0.47 & 0.37 & & \\
\hline Educated blue collar & 4.35 & 0.00 & 2.30 & 0.07 & & \\
\hline Self employed/free-lance & -2.99 & 0.00 & 11.07 & 0.00 & & \\
\hline \multicolumn{7}{|l|}{ Education dummies (basic) } \\
\hline Lower vocational & 9.65 & 0.00 & -2.21 & 0.13 & & \\
\hline Medium vocational & 8.13 & 0.00 & -4.02 & 0.03 & & \\
\hline Craft education & 8.79 & 0.00 & -3.17 & 0.05 & & \\
\hline High vocational & 10.35 & 0.00 & -2.99 & 0.12 & & \\
\hline College & 10.82 & 0.00 & 0.56 & 0.39 & & \\
\hline University & 12.65 & 0.00 & 0.66 & 0.40 & & \\
\hline \multicolumn{7}{|l|}{ Age dummies (<20 years) } \\
\hline $20-30$ years & 0.94 & 0.31 & -2.76 & 0.28 & 0.76 & 0.00 \\
\hline $30-40$ years & -0.29 & 0.43 & -4.54 & 0.17 & 0.42 & 0.00 \\
\hline 40 - 50 years & 0.14 & 0.47 & -6.38 & 0.06 & -0.11 & 0.27 \\
\hline $50-60$ years & -0.12 & 0.47 & -6.94 & 0.02 & -0.95 & 0.00 \\
\hline$>60$ years & & & & & -2.62 & 0.00 \\
\hline$\sigma_{\varepsilon_{i}}$ & 12.66 & 0.00 & 11.11 & 0.00 & & \\
\hline$\rho_{\varepsilon_{i} \mu}$ & -0.14 & 0.18 & 0.12 & 0.35 & & \\
\hline$\rho_{\varepsilon_{1} \varepsilon_{2}}$ & & & -0.23 & 0.00 & & \\
\hline Log Likelihood & & & & & & -1744.55 \\
\hline Pseudo- $R^{2}$ & & & & & & 0.40 \\
\hline
\end{tabular}




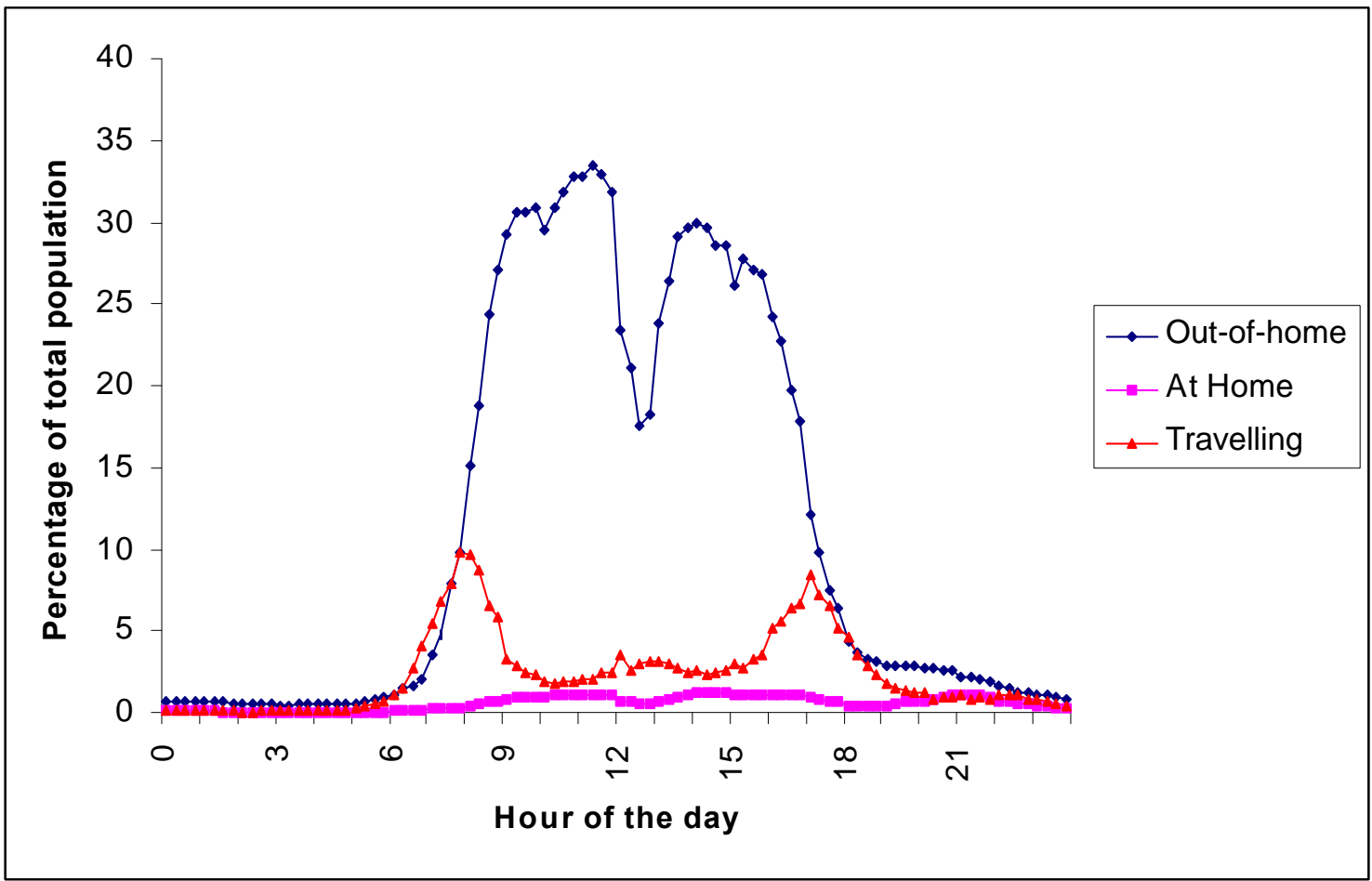

Figure 1: Distribution of (paid) working at home and out-of-home and travelling (for all purposes) across the day (monday-friday average) (Source: SCP, 1995). 


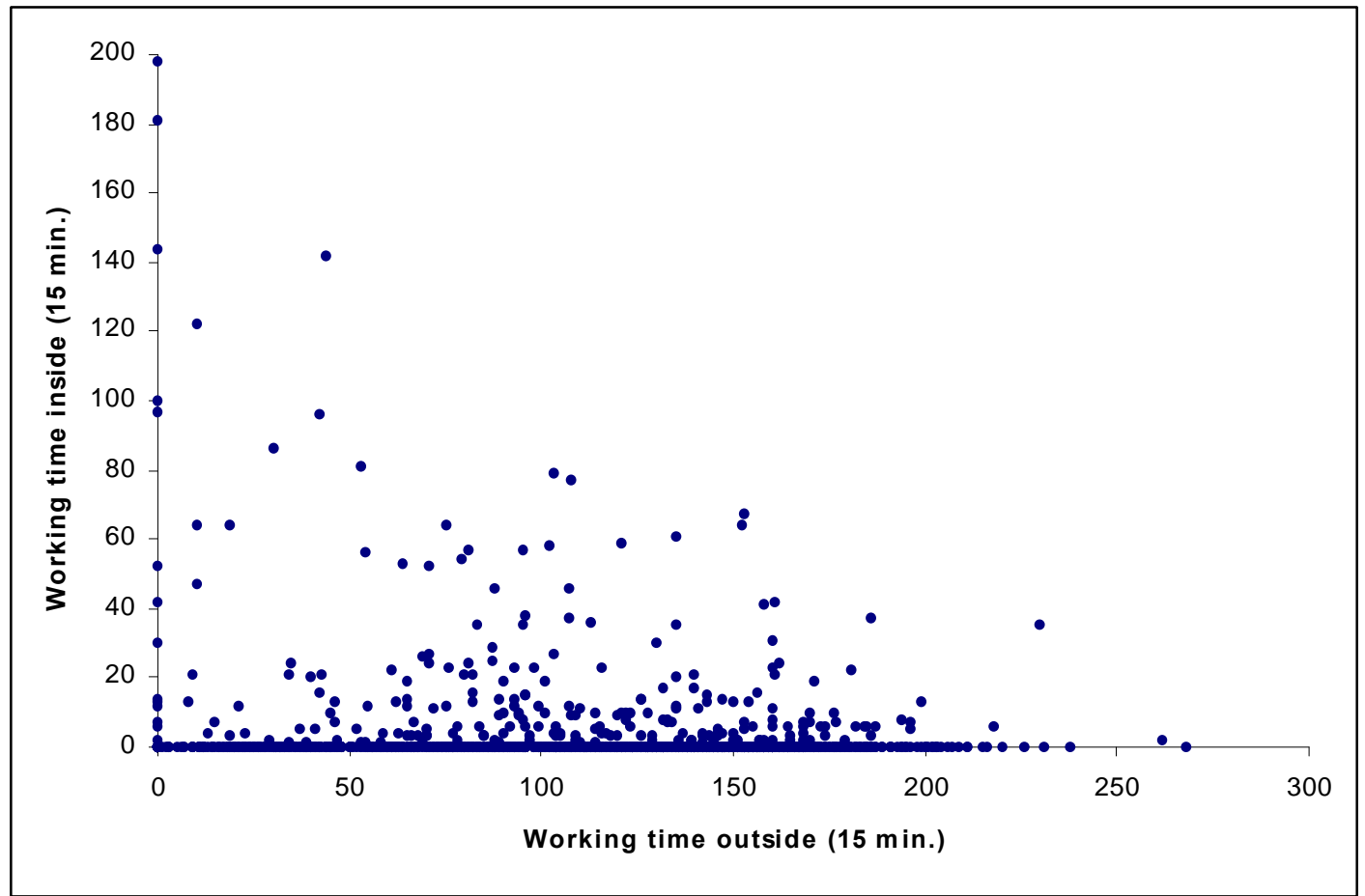

Figure 2: The relation between quarters of an hour working at home $(\mathbf{Y})$ and out-of-home $(\mathbf{X})$ per week. In regression terms: $\mathbf{Y}=5.88(0.74)-0.027(0.006) \mathbf{X}$, with standard errors between parentheses (Source: Tijdsbestedingsonderzoek, 1995). 


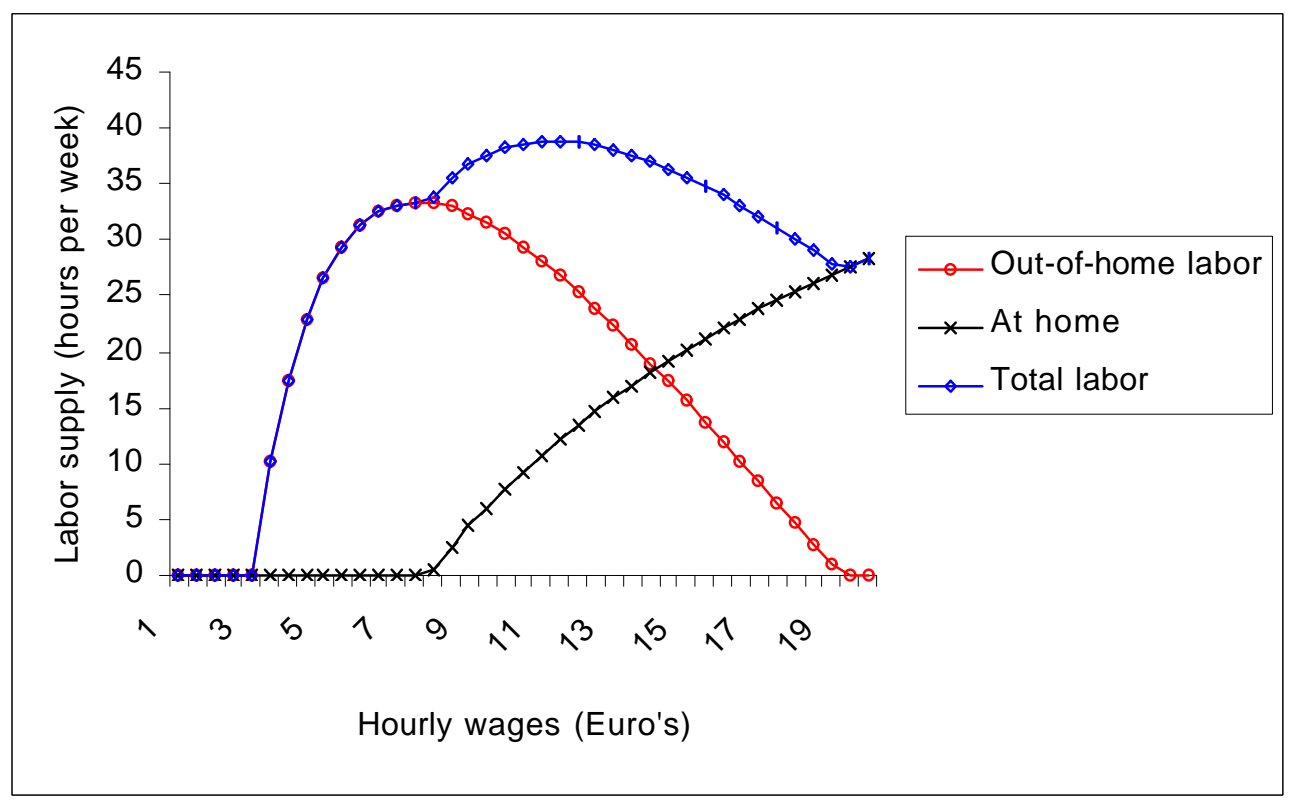

Figure 3: Figure 3: Simulated relations for married high skilled white collar male workers, with university education, between 30 and 40 years old, and in modem possession between net hourly wages and weekly labor supply using the estimation results from Table 3. 